So how to relate - to each other, to something? Cognizant of our own entanglement with institutional structures and infrastructures, with this volume we want to suggest, on the one hand, that we understand knowledge as a relational process in which our own involvement always plays a part; and, on the other hand, to reflect on which networks of relations we ourselves can initiate or create: relations of decision making, of exchange and cooperation, of devising documentation, distributions, and figurations of knowledge, and on how to keep them open for appropriation and mediation by others. Against a formalism of relation that presents relationality of artistic-academic practice as a value in and of itself, we thus understand the contributions as a plural guiding thread or line of flight for a multidirectional work on the political.

In this sense, we would like to conclude by mentioning another aspect that is implicitly or explicitly echoed in various contributions: that of futurity. What other futures can be imagined and created through different relationalities? Because eventually, relational issues do not conclude with the question of how to but immediately lead to another: that of what for.

\title{
Melanie Sehgal \\ Techniques as Modes of Relating: \\ Thinking with \\ a Transdisciplinary Experiment
}

"How to relate?" Posed as a question, this could be read either as an epistemological problem concerning something that needs to be clarified before it is possible to relate. Or it could be read as praxeological problem, such as can be found in a manual or a recipe: "How to ..." - in this case - "relate?" The question thus poses a problem either to theory or to practice. Both options place us firmly in a modern, Western framework, because it is within this modern framework that relating has become a problem. This trajectory of thought, broadly construed, is marked by a metaphysics of individualism: individuals are thought of as self-containing entities without intrinsic relations. Within this frame of thought, relationality is therefore something that comes after individuals have already been constituted (or have constituted 
themselves) - hence the urgency of the question "How to relate?" Relating requires explanation.

This question has prompted many attempts to construct relational ontologies for example, in recent feminist science studies (Donna Haraway, Karen Barad, Isabelle Stengers) and in early twentieth-century process philosophies from Henri Bergson, William James, and Alfred North Whitehead, to name the resources I am thinking with here. ${ }^{1}$ However, in my view, we still cannot avoid inheriting this modern frame of thought today, no matter what field we are in, because these dominant modes of thought have sedimented into our common sense, our language, and into the material-semiotic dispositives in which we work, think, live, and feel. The crucial question in my view is thus precisely how to inherit this troubled legacy today. The question of inheritance - understood as something active and creative that can be tackled in various ways - is what seems to be at stake when we inquire into how heterogenous participants can relate within practices of knowledge production.

But even if both options - the epistemological and what one could call the praxeological response to a modern negligence of relationality - force us to inherit a modern legacy, they do so in decisively different ways. The first option, the epistemological phrasing, remains firmly within a modern framework because modern epistemology from René Descartes and Immanuel Kant onwards is precisely marked by the question of how a subject can relate to its object - even when those other objects are subjects, understood as (self)conscious human beings. It starts with, or posits, the subject and then asks: how can the relation to an object be achieved? how is it structured? This is very schematic, of course, but what I wish to emphasize is that within this frame of thought the relation is not given; it is problematic and fragile (hence the constant threat of being duped that haunts modern epistemology). Furthermore, the relation only figures as a relation between two already constituted things, subject and object(s). Addressing the question "How to relate?" in this first sense therefore necessitates looking at its presuppositions: why is relating a problem in the modern framework, specifically when it comes to knowledge?

Within my toolbox I would go to the philosophy of Alfred North Whitehead and his critique of the "subjectivist principle" that Descartes and Kant have firmly settled into our modern philosophical framework. Within a frame of

1 See, for example, Haraway, Donna, Staying with the Trouble: Making Kin in the Chthulucene, Durham, NC / London 2016; Barad, Karen, Meeting the Universe Halfway: Quantum Physics and the Entanglement of Matter and Meaning, Durham $\mathrm{NC}$ and London 2007. For process philosophy, see James, William, Essays in Radical Empiricism, Cambridge, MA / London 1976; Whitehead, Alfred North, Science and the Modern World, New York 1967; Whitehead, Alfred North, Process and Reality: An Essay in Cosmology, New York 1985. Isabelle Stengers connects these two fields, science and technology studies (STS) and process philosophy, for example in Stengers, Isabelle, Thinking with Whitehead, Cambridge, MA / London 2011. 
thought governed by the "subjectivist principle," subjectivity is conceived of according to a substance-quality mode of thought: a subject is a substance that has predicates or qualities, and it can only ever be a subject, never a predicate. ${ }^{2}$ The outcome of these assumptions - which remain mostly implicit even within philosophy - is a notion of a solipsistic self for which relating is precisely a problem, something that needs explanation rather than being a given. In contrast, I would like to spell out a pragmatist conception of knowing, because from a pragmatist perspective, relating is not a problem at all: relations abound that are given in experience and hence form the starting point of thought. William James has most prominently insisted on taking relations seriously in philosophy, pointing to a whole universe, or rather a "pluriverse," of relations that can be classified in degrees of intimacy: from the relations of "mere withness in a universe of discourse," to the most intimate relations, which he defines as the relations within the mind and for which he coined the term "stream of consciousness."

Relations are of different degrees of intimacy. Merely to be "with" one another in a universe of discourse is the most external relation that terms can have, and seems to involve nothing whatever as to farther consequences. Simultaneity and time-interval come next, and then space-adjacency and distance. After them, similarity and difference, carrying the possibility of many inferences. Then relations of activity, tying terms into series involving change, tendency, resistance, and the causal order generally. Finally, the relation experienced between terms that form states of mind, and are immediately conscious of continuing each other. The organization of the self as a system of memories, purposes, strivings, fulfilments or disappointments, is incidental to this most intimate of all relations, the terms of which seem in many cases actually to compenetrate and suffuse each other's being. ${ }^{3}$

Thus, for James, the question is not whether there are relations or not but rather which type of relationality we are dealing with. Even an apparent nonrelatedness is in fact a specific type of relation in his relational process philosophy: a disjunctive relation. And, crucially for James, the psychologist, consciousness, the most intimate part of the human mind, is relational too, not a self-contained individual. Hence, not even what we commonly call the subject is simply a substance, present to itself - it's relations all the way down. What counts for the stream of consciousness, counts all the more for knowledge.

2 "The subjectivist principle follows from three premises: (i) The acceptance of the 'substance-quality' concept as expressing the ultimate ontological principle.

(ii) The acceptance of Aristotle's definition of a primary substance, as always a subject and never a predicate. (iii) The assumption that the experient subject is a primary substance." See Whitehead 1985, p. 157.

3 James 1976, p. 23. 
Knowledge for the pragmatists is relation. It is about making connections between all kinds of parts of experience, understood in James's metaphysical sense, and agents, human or not. ${ }^{4}$ It is about drawing inferences, conclusions, and speculating - and precisely not about creating mirror images or reflections between two distinct relata, two solipsistic individuals. In a pragmatist vein, then, subject and object are outcomes of these pluralistic ways of relating, not their starting point. From this perspective, relating is a problem only of theory - of a particular tradition of philosophy, which has notoriously overvalued a particular kind of relation, the "disjunctive relation" and not of practice and experience. This manifests in everyday life where no one would or could deny relationality unless they were in a pathological condition. Hence James points out that not taking into account relations, or more precisely in his words the continuous relation, is "the strategic point, the position through which, if a hole be made, all the corruptions of dialectics and all the metaphysical fictions pour into our philosophy." ${ }^{5}$

Departing from this general outline of the epistemological reading of the question "How to relate?" I will now continue along the line of the second reading of the title: the praxeological sense of a manual, or recipe: "How to do this thing, to relate - practically?" If we accept the presupposition that relations are everywhere - they are what we start from rather than the relata in a metaphysics of individualism - the question "How to relate?" is not redundant, but simply shifts slightly. The mode of relating comes into focus: how do we relate? Which ways of relating do we want to continue, repeat, experiment with, and which ones do we seek to avoid? Within a relational ontology that, too, involves the question: who do we want to become? An ethics and pragmatics of relating unfolds because relating is, of course, not per se a good thing: some relations in some contexts are poisonous and destructive, in others they might be a remedy. Hence, far from becoming redundant, the question of "How to relate?" is, in this second perspective, rephrased as a practical and historical problem rather than being an epistemological and theoretical one. However, the question remains: why did relating - between different practices, different modes of knowledge production - become a problem at all within a modern framework that we still inherit today?

\section{Experimenting with Modes of Relating}

I would like to think about this question with and through a project that I have been engaged with for a couple of years now: the transversal and multidisciplinary working group FORMATIONS, which consists of practitioners from various disciplines, including the arts, philosophy, human geography,

4 James coins the term "pure experience" to denote a realm that precedes individual or phenomenological experience: a world of pure experience that marks the starting point for thought and the cornerstone of his empiricism. See James, William, "Does 'Consciousness' Exist?" in James 1976, pp. 3-19.

5 James 1976, p. 25. 
computational biology, yoga, urban design, cultural and literary studies, and political activism, initiated and led by the artist Alex Martinis Roe and myself. ${ }^{6}$ And, in fact, "How to relate?" was precisely the question we started from: could we relate, across our differences, across our training in the different departments of the modern constitution, in different specializations that are perhaps not meant, and definitely not trained, to relate? And if this were possible, how? What I want to do in the following is create an interference pattern between this project, FORMATIONS, and some theoretical and historical reflections that stem from my own practice as a philosopher. I'll go back and forth between the two and will spell out some aspects that have been implicit in our work as a group, which didn't start from a set agenda but simply from the insistent question: could we relate ${ }^{7}$ In doing so, I would like to explore the idea of knowledge production as a (set of) technique(s). And techniques, as I will show, are inherently relational. What I want to suggest is that looking at knowledge production - in the widest sense, including nonacademic forms of knowledge production - as a set of techniques might be an interesting perspective today, when the problematic repercussions of modern conceptions of knowledge have become increasingly hard to ignore. In the face of what has come to be called the Anthropocene (or Capitolocene or Cthulucene), ${ }^{8}$ it seems clear that we need to rethink our modes, and not only the content of knowledge production - could that work through considering knowledge as relational techniques? What does that imply? What could be the particular relevance and gain of thinking about knowledge as techniques, and of techniques as modes of relating?

FORMATIONS approached these questions first on the level of format: how to facilitate and enable a truly transdisciplinary encounter? In 2015, the first year of the project, we met as a closed group for daylong workshops that were meticulously prepared and curated by Alex and myself, because our attempt was to take into account everything that goes into such an encounter: the spatial setup, the temporal framing, the modes of documentation. This was important to us because in our experience, in inter- and transdisciplinary settings and events, people from different disciplines were often brought together in a way that already makes a number of assumptions and implicitly privileges some of the practices present. For example, gathering practitioners around a table to discuss a topic confers a primacy to the spoken word as

6 FORMATIONS began in 2015 with a series of workshops in the Berlin Haus der Kulturen der Welt and has been hosted by various cultural institutions since then as well as developed into collateral events in resonance with the workshops. See www.formations.link (last access: October 4, 2019).

7 I should add that what follows is my personal perspective on the collective experience of FORMATIONS; I think and hope each of us will tell a slightly different story.

8 For an exemplary treatment, see Haraway 2016, who offers a problematization of the term "Anthropocene" as well as Tsing, Anna, Swanson, Heather, Gan, Elaine, and Bubandt, Nils (eds.), Arts of Living on a Damaged Planet: Ghosts and Monsters of the Anthropocene, Minneapolis 2017. 
well as to the panel format - both are tacitly presumed by, but most likely are not part of, the represented practices in the same way, thereby creating an asymmetric and restricted starting point for the encounter.

Each of these initial FORMATIONS workshops specifically centered around an encounter between two of our practices while engaging the other practices from this vantage point. For example, we paired the computational biologist Roman Brinzanik with the musician Hendrik Weber (aka Pantha du Prince) around the topic of "patterns": we conducted listening experiments, watched both of them working with specific but visibly comparable computer programs, and got involved in a long discussion on the role of the sense of hearing in the sciences and for knowledge production at large, as well as on the hierarchy of the senses in the arts and sciences. During the period of preparation and as a physical manifestation (instead of documenting the process), we created what we call a "diffraction," a record of an interference pattern between two practices. ${ }^{9}$ In the case of Brinzanik and Weber, the diffraction pattern consisted of a sonification of data from the computational biologist's research with cancer patients in a New Jersey clinic, created using the software and the sounds of the musician. This sonification was not meant to be a product; instead, it crystallized our previous discussions, held over weeks, and made them tangible - by auditory means - to the larger group. It sparked and oriented the common discussion in very interesting and rich ways and became a placeholder for, and reminder of, the discussions afterwards. ${ }^{10}$

9 We worked with the term "diffraction" in Haraway's sense in order to replace the notion of reflection and representation that seems inherent to the idea of documentation: "Diffraction patterns record the history of interaction, interference, reinforcement, difference. Diffraction is about heterogeneous history, not about originals. Unlike reflections, diffractions do not displace the same elsewhere, in more or less distorted form, thereby giving rise to the industries of metaphysics. Rather, diffraction is a metaphor for another kind of critical consciousness at the end of this rather painful Christian millennium, one committed to making a difference and not to repeating the Sacred Image of the Same. ... Diffraction is a narrative, graphic, psychological, spiritual, and political technology for making consequential meanings." See Haraway, Donna, Modest_ Witness@Second_Millennium.FemaleMan@_Meets_OncoMouseTM: Feminism and Technoscience, New York 1997, p. 273. See also Barad 2007, p. 73 for a more ontological and quantum-based understanding of the physical phenomenon of diffraction, as well as Sehgal, Melanie, "Diffractive Propositions: Reading Alfred North Whitehead with Donna Haraway and Karen Barad" in Parallax, vol. 20, no. 3, 2014, pp. 188-201 for a further exploration of the term for the production of theory.

10 For an excerpt of the sonification, see FORMATIONS: Propositions, Stories and Sketches for Transdisciplinary Encounter, lecture performance with Alex Martinis Roe, Melanie Sehgal, Roman Brinzanik, Deborah Haaksman, Rebekka Ladewig, Julian Schubert, and Hendrik Weber at Wisdom Techniques as part of Technosphere X Knowledge, Haus der Kulturen der Welt, Berlin, April 16, 2016, www.hkw.de/en/app/mediathek/video/69808 (last access: October 3, 2019). 


\section{In the Groove of Modern Bifurcations}

FORMATIONS thus started out from a concern that today seems more and more widely shared - a sense that the ways in which knowledge is preponderantly produced no longer seem adequate to contemporary problems and issues. The climate crisis, the depletion of the earth being regarded as a resource, and the massive destruction of life forms seem, by their very nature, to call for transdisciplinary responses. In fact, one could stipulate that specialization as it came to mark the academic landscape since the nineteenth century is not wholly innocent in bringing about this situation. Specialization, of course, has generated a wealth of in-depth knowledge, but at the same time it forecloses a look at the wider consequences of one's knowledge production. Specialization creates, in Whitehead's words "minds in a groove" that are blind to the wider ethicopolitical repercussions of their specific way of knowledge production. In Science and the Modern World, a work that preceded and prepared Whitehead's opus magnum of speculative philosophy, Process and Reality, Whitehead writes:

Each profession makes progress, but it is progress in its own groove. Now to be mentally in a groove is to live in contemplating a given set of abstractions. The groove prevents straying across country, and the abstraction abstracts from something to which no further attention is paid ... The remainder of life is treated superficially, with the imperfect categories of thought derived from one profession. ${ }^{11}$

In this book, Whitehead remarks that the most important invention of the nineteenth century was the method of training professionals in the sciences a statement that seems striking in view of the wealth of knowledge, new disciplines, and technologies that the nineteenth century brought on. However, it resonates with what recent scholars in the field of science and technology studies (STS), such as Lorraine Daston and Peter Galison, John Tresch, or even someone as early as Ludwik Fleck, have pointed to: that knowledge, even in the sciences, is much less about propositional, rational knowledge than we commonly think or are made to think, but that it is rather much more about bodily and mental habits of perceiving, of intuiting, about implicit or tacit knowledge as Michael Polanyi put it. ${ }^{12}$ Hence, knowledge production is addressed here as a praxeological, not merely an epistemological, problem.

11 Whitehead 1967, p. 197.

12 Fleck, Ludwik, Genesis and Development of a Scientific Fact, Chicago 1979; Fleck, Erfahrung und Tatsache: Gesammelte Aufsätze, ed. Lothar Schäfer, Frankfurt/M. 1983; Polanyi, Michael, Personal Knowledge: Towards a Post-Critical Philosophy, London 1958; Polanyi, The Tacit Dimension, London 1966; Daston, Lorraine, and Galison, Peter, Objectivity, New York 2007; Tresch, John, "Anthropotechnics for the Anthropocene," in Technosphere Magazine, 2016. This latter text was originally an introduction to the event Wisdom Techniques at the Berlin Haus der Kulturen der Welt, during which FORMATIONS presented their work. 
Fleck, for example, draws on Gestalt psychology to show how professional training in the experimental sciences is about learning to see certain things and not others, to pay attention to certain things and not to others. ${ }^{13}$ One thereby unlearns the capacity to see or perceive what the layman or what the same person before her training as, say, a bacteriologist would have actually seen. One could even widen this focus towards the apparatuses of knowledge production because techniques are not restricted to human actors: the experimental dispositive, for example, would then appear as a technique for excluding the multifariousness of the world, and for carving out a box, for materially reducing the elements that come into play, for paying attention to what is inside the frame, not outside of it. One might think that this is a much broader topic for science and technology studies than it actually is, but the field was constituted precisely in opposition to the heroic narratives that would tell the history of the sciences as histories of its human actors, of important men and their "discoveries." In contrast, STS set out to focus on the materiality, the apparatuses of knowledge production, pointing out that agentiality is not limited to human actors but lies in the entanglement of a multitude of actants, which are material, discursive, human, technological. Consequently, there was less focus on the people who produced knowledge, on their bodily, affective, and cognitive training. It is important to note that thinking about the importance of techniques as one factor within the process of knowledge production, as I propose to do here, does not imply reverting to the grand narratives of the history of science but precisely aims to take into account the transindividual relations between people, apparatuses, and nonhuman actors in the making.

If one thinks of disciplines not only as specific contents or specific bodies of knowledge, but as specific techniques of paying attention and of forgetting, of including and excluding, and as ways of habitualizing these ways of paying attention or not, then it becomes apparent that historically, since the nineteenth century, a great deal of training went into not relating, into isolating and specializing. This is not per se problematic because only through marking off a field can we come to stabilize an object of knowledge at all. But there are problematic side effects if this reduction of a field becomes reified, rather than being understood as what it was: a pragmatic reduction. In consequence, it is no longer possible for the practitioners to see outside this box, i.e., to fathom the limits of their inquiry and its relations to other fields of experience and knowledge.

The references to FORMATIONS have been eliminated in the published version but remain in the video of Tresch's talk: There Are No Religions and Science Is One of Them, April 16, 2016, www.hkw.de/en/app/mediathek/video/50395 (last access: October 4, 2019).

13 See in particular Fleck, Ludwik, "Schauen, Sehen, Wissen" in Fleck, Denkstile und Tatsachen: Gesammelte Schriften und Zeugnisse, ed. Sylwia Werner and Claus Zittel, Berlin 2011. 
The history of specialization that has come with the differentiation of the academic landscape since the eighteenth and nineteenth centuries was therefore both a starting point for our work in FORMATIONS as well as a first attempt to reply to the question, posed at the beginning of this paper, of why relating has become a problem within the modern framework at all. Another aspect in this regard and an important point of departure for FORMATIONS was that these specialized forms of knowledge production perpetuate implicit assumptions without ever questioning them: assumptions that categorically separate nature and culture, body and mind, sex and gender, knowing and believing, the modern and the nonmodern. Of course, such dichotomies have been subject to extensive theoretical critique in the past decades, but our sense was that they nevertheless persist practically, particularly in institutionalized spaces such as universities, museums, and public and private cultural institutions as well as in funding structures. They persist simply by means of the material-discursive set-up of institutionalized spaces and by means of the techniques in which one is trained when studying a certain discipline - and again, by discipline I mean scientific disciplines as well artistic and bodily practices. Historically specific, theoretical assumptions are entrenched in our practices by the way we use spaces and language, by the ways we engage our bodies (or not), by the way we interact with colleagues, students, financial bodies, and publishing industries. Each of the members of FORMATIONS have experienced the resulting sense of inadequacy in our working contexts, each in our own way in our specific working environments, institutions, and disciplines (this was one of our criteria when Alex and I were scouting members for FORMATIONS).

\section{Towards an Ecology of Practices}

I'll give my personal example of this sense of inadequacy in my context, the university, and more specifically, a cultural studies department: in my work I draw on a specific reading of the modern constellation that I take from the philosophy of Whitehead and that was also very important for the setup of FORMATIONS. It's one of many ways of accounting for the modern divides - nature/culture, body/mind, subject/object, modern/nonmodern. However, to me Whitehead's diagnosis is singular in that it not only simply describes or criticizes these divides but shows how they work and proposes a speculative narrative about how they came to be, historically and systematically. Whitehead points to an inconsistency in the modern concept of nature that actually harbors two understandings of nature that are mutually incompatible with one another: there is, on the one hand, nature as it is perceived (by human subjects) and, on the other, nature as it is per se, as an object of knowledge that is never perceived directly but needs mediation, for example in a scientific experiment. Whitehead speaks about the "bifurcation of nature" because the link between these two conceptions is very difficult 
or rather impossible to make. ${ }^{14}$ My problem is that it is very hard to work around this bifurcated concept of nature in a university because its assumption is built into the very foundation of each university - simply think of the division of departments into natural sciences and humanities and how each methodologically claims to be able to explain and thus overpower the other. For Alex Martinis Roe, as a practitioner in the artworld, the crucial dichotomy was what she calls the artworld's "development-presentation model." In that model, the studio is thought of as a lonely place, where the artist works alone on objects which are then made public in exhibitions. Her practice, however, involves designing modes of encounter, as a way of making artworks, which then also become settings for dialogue and exchange. ${ }^{15}$ Since this involves lots of other people at every stage of the process of making, for her, like many others today, the persistence of the model of development (in the studio) and presentation (in the gallery) with its emphasis on the finished product seems to be a very artificial separation and one that perpetuates a modernist model of subjectivity that I problematized at the outset of this essay, the solipsistic self. In the same vein, the notion of a general public implied in this model seems to be too abstract. In contrast, the networks that generate a specific audience for a specific exhibition are of great interest to Alex and she is actively concerned with both, engaging and generating that network. Because of this she was often faced with the dilemma of wanting to try out her situation designs in an in-between-space - neither the museum nor the studio - and for her, FORMATIONS has provided that space. Hence, FORMATIONS started out from diagnosing this situation in which dichotomous theoretical assumptions have sedimented into our practices and institutions, into habits of thought, action, and feeling. Our conclusion from this was that it is not enough to criticize these habits of thought theoretically. Rather, for us this seemed to call for practical responses. This is why we, maybe naïvely, immediately jumped into doing rather than unravelling historical and theoretical references first, as I am doing here now. We were interested in the specific encounter of the specific practices and people that we gathered; we were curious about the specific processes generated by these encounters and to see how and if we could learn to speak with one another across disciplinary divides. We were curious how, with the histories of

14 "What I am essentially protesting against is the bifurcation of nature into two systems of reality, which, in so far as they are real, are real in different senses. One reality would be the entities such as electrons which are the study of speculative physics. This would be the reality which is there for knowledge; although on this theory it is never known. For what is known is the other sort of reality, which is the byplay of the mind. Thus there would be two natures, one is the conjecture and the other is the dream." See Whitehead, Alfred North, The Concept of Nature, Amherst and New York 2004, p. 30. For a more thorough discussion of this Whiteheadian reading of modernity see Sehgal, Melanie, Eine situierte Metaphysik: Empirismus und Spekulation bei William James und Alfred North Whitehead, Konstanz 2016.

15 See alexmartinisroe.com (last access: October 4, 2019). 
specialization that we were per force inheriting, we could relate to each other's practices, concerns, questions.

Félix Guattari's notion of three intertwined ecologies served as an important conceptual tool allowing us to take first steps across disciplinary divides, especially as he situates the necessity to think against the grain of accustomed habits of thought in what today would be called the Anthropocene and its cognates. Guattari insists on the importance of the interplay between three ecologies, the environmental, the social, and the mental ecology:

Our survival on this planet is not only threatened by environmental damage but by a degeneration in the fabric of social solidarity and in the modes of psychical life, which must literally be reinvented. The refoundation of politics will have to pass through the aesthetic and analytical dimensions implied in the three ecologies - the environment, the socius and the psyche. We cannot conceive of solutions to the poisoning of the atmosphere and to global warming ... without a mutation of mentality, without promoting a new art of living in society. ${ }^{16}$

Responding to our contemporary situation, then, requires the production of different kinds of subjectivities as well as an experimentation with different kinds of anthropotechniques in order to do so. Hence, Guattari's conception of three intertwined ecologies guided our first discussions and the ways we set up our workshops.

Rephrasing this with a concept coined by Isabelle Stengers, what we tried to do is to create a space for an "ecology of practices" - a space in which practices can encounter one another without one practice, one form of knowledge overpowering the others. ${ }^{17}$ This Stengerian conception is to me the most elaborate theoretical proposition to answer the question "How to relate?" within a modern setting because it takes the difficulties into account that relating faces here. 18 These difficulties result precisely from that fact that modern divisions have sedimented in our practices and partly ossified. For Stengers, the crucial point in relating across differences is therefore the way of address, the way of posing questions to one another. For her, there is an art of posing questions to be developed, of posing questions that interest the other as a practitioner of a respective field without, however, stemming from this field and, most importantly, without the participants insulting one another. Stengers developed her approach in the face of the so-called science wars, when social scientists began to explain the practices of the natural sciences as a social practice like any other and thus explained away what actually

16 Guattari, Félix, Chaosmosis: An Ethico-Aesthetic Paradigm, Sydney 1995, p. 20.

17 Stengers, Isabelle, Cosmopolitics, Minneapolis 2010.

18 For a more detailed discussion of Stengers's notion of an ecology of practices see Sehgal, Melanie, “Aesthetic Concerns, Philosophical Fabulations: The Importance of a 'New Aesthetic Paradigm,'” in SubStance, vol. 47, no. 1, 2018, pp. 112-129. 
mattered to these practitioners, which presupposed precisely that what they were doing was not only social. One could say that this is a very modern strategy: one practice tries to explain all the others in its own terms - initially, physics did this by trying to explain everything reductively in terms of a Newtonian conception of matter; today neuroscience perhaps strives to claim this position, but the social sciences as well as cultural studies have entered the fray, too ... For Stengers, the conception of an ecology of practices is an attempt to substitute such an "ecology of prey and predator" with a framework in which modes of relating between practices become possible that do not impose hierarchies and try to explain other practices away and that allow for ways of relating not in spite of but in view of their differences. Here, the figure of the diplomat is an important metaphor for this type of relationality. It must be ensured in such an encounter across differences that each practitioner who has been addressed within such a setting may return to their colleagues without being regarded as a traitor. Thus, the questions posed to the practitioner cannot be insulting. They do not need to be confined to the questions that already animate a certain field, but they must be capable of interesting the practitioners as practitioners. The questions pertinent to an ecology of practices then aren't confined to what a practice is but are posed in view of what it might become.

\section{Techniques as Modes of Relating}

How does the practice of FORMATIONS resonate with these theorizations? What we attempted was to explore and invent intersections between our different ways of working, which per se were located on different sides of the modern divides. With a special awareness of the circumstances we were inheriting, the first step was to question the givens of specialized habits of thought and, therefore, to closely examine the implicit assumptions inherent to our material-discursive set-ups and our practices. These formats and practices were our starting point, and from there we tried to shift specific elements, while keeping others as they were, in order to see how that would change our way of encountering these different practices.

We began from analyses of each practitioner's specific methods and focused on aspects in which the limits of disciplinary boundaries had already become manifest. Hence, for each of the workshops, we experimented with the dispositive, i.e., discursive, spatial, temporal, and other material conditions, and tried to find points of convergence and divergence between the two practices in focus, rather than defining a common project in advance. In other words, we tried to generate a diffraction, an interference pattern, between the two practices. From there we speculatively generated a term that we then used as a focus for each of the workshops, less as a common denominator but rather as a shared concern, or a proposition - a perspective through which we looked at the two practices and their overlaps and differences. The terms were patterns, examples, cases, visions, and attitudes. These keywords came 
out of our specific processes and we felt that they capture important elements of knowledge production that need to be addressed when speculating about knowledge beyond modern binaries.

We found that despite all our differences - we didn't have the same backgrounds, competences, practices, content, or problems - we could relate to one another and the respective practices, questions, and problems if we focused on techniques, on what we were practically doing and how we had been trained. We found that we could relate using the other practices as a kind of prism onto our own, and also if we worked towards creating techniques together, techniques of transdisciplinary encounter. This is how our work together continued after the initial workshops. At the moment, and partly as an outcome of the workshop described above, we are specifically working on techniques of listening. Listening obviously plays a crucial role in relating across difference: it's the first step in relating and much more than merely hearing what somebody else says - really listening is about letting go of one's assumptions and givens, of what one takes for granted, and of working through these assumptions towards an openness for difference and one's own becoming. As this is neither an easy nor a common thing to do, our inherited ways of knowing require, in our view, new techniques of listening.

The outcome of this first phase of work together then was this specific focus on techniques. By way of conclusion I would like to ask: what actually is a technique? The term refers back to the Greek notion of techne, meaning art, not in the modern sense of a particular kind of object (aesthetics), but in the sense of artistry, skill, or craftsmanship. ${ }^{19}$ Techne for the Greeks had a close relation to episteme: it is a kind of knowledge and it is a kind of knowledge that refers to the arts, crafts, and sciences alike. ${ }^{20}$ Technai are part of a continuum of different modes of knowing that range from sense impressions and memories to experience and finally to systematic knowledge. ${ }^{21}$ In distinction from the specific kind of knowledge that takes the form of habits, knowledge in the form of technai involves purpose and a certain level and kind of consciousness. It is knowledge that follows rules and involves a theoretical or practical ability - a capacity for action, rather than the action itself, based on a logos. The test for techniques is pragmatic: they either work or they don't. In a similar pragmatic vein, the criterion that decides whether someone actually has technical knowledge in the developed sense is if she can teach it. Hence, teachability and relatability are the criteria that decide if a particular kind of knowledge is actually a technique. ${ }^{22}$ Techniques then are per

19 Interestingly for the question of how to relate between different compartments of knowledge within modernity, technē in Latin translates not only into ars and technica but also disciplina.

20 Mitcham, Carl, "Philosophy and the History of Technology" in Bugliarello, George and Doner, Dean B. (eds.), The History and Philosophy of Technology, Chicago and London 1979, pp. 163-201, here p. 173.

21 Aristoteles, Metaphysics I, Book 1, London 2009, 980b, p. 4ff. and Mitcham 1979, p. 175.

22 Mitcham 1979, p. 173 und Plato, "The Ion," in Ion, Hippias Minor, Laches, Protagoras: The Dialogs of Plato, trans. R.E. Allen, New Haven and London 1996, 532c, p. 12. 
se modes of relating, classically between different generations in a teacherstudent relation. Last but not least, technai involve an ethos, because of their relationality but also, in a connected sense, because they are concerned with their consequences, with what they produce in the world of experience.

These characteristics make techniques a promising candidate to develop conceptual tools that cut through accustomed divisions inherited from modern frameworks: they refer to the arts, crafts, and sciences alike and point to the element of artistry and skill inherent in all of them - the necessity for training oneself in particular modes of doing, thinking, perceiving, and sensing. What seems most important to me however, not just regarding FORMATIONS, is that they do not imply a distinction between the modern and the nonmodern. Centering our attention on techniques, rather than on disciplines or specific content, thus helped us to sidestep the binary between modern and nonmodern practices, which we had to accommodate in our heterogeneous group of participants coming from the natural sciences, the humanities, and the arts as well as physical and spiritual practices. Working on creating techniques of transdisciplinary encounter in experimental and often playful ways was our way to respond to our quest for practical responses to the insufficiencies and the persistence of modern habits of thought. And maybe it is even from such kinds of reflection on transversal encounters in practice that a relational epistemology - looking at the diffraction of practices and their interference patterns - may emerge.

As befits the subject of this paper, many minds and bodies contributed to it. I would like to especially thank Alex Martinis Roe, all members of FORMATIONS of its first phase Roman Brinzanik, Descha Daemgen, Deborah Haaksman, Rebekka Ladewig, Wietske Maas, Julian Schubert, Hendrik Weber, and Thilo Wiertz - as well as the editors of this book, especially Maximilian Haas and Annika Haas.

\section{Sibylle Peters \\ How to Relate Differently: Scenes of Shared Research \\ from the Programs \\ "Performing Citizenship" and "Assemblies \& Participation"}

How do we relate - when we gather, when we assemble, when we speak for each other, when we claim our rights and fight for them? How do we relate through the performance - or the performative dimension - of assembling, of decision-making, of representing and protesting? How do people start to relate differently in these practices? And are the respective shifts and changes connected to that performative dimension? These questions have 